\title{
The use of historic flood events to reduce uncertainty in future flood frequency predictions: a bootstrap method
}

\author{
Anouk Bomers ${ }^{1, a}$, Ralph M.J. Schielen ${ }^{2,3}$ and Suzanne J.M.H. Hulscher ${ }^{1}$ \\ ${ }^{1}$ University of Twente, Faculty of Engineering Technology, Enschede, the Netherlands \\ ${ }^{2}$ Ministry of infrastructure and Water Management, Arnhem, The Netherlands \\ ${ }^{3}$ Delft University of Technology, Delft, The Netherlands
}

\begin{abstract}
Flood frequency relations are generally highly uncertain for large return times due to the relatively short data set of annual maximum discharges. This extrapolation uncertainty can be decreased by extending the data set with historic flood events. However, two problems arise if a traditional flood frequency analysis should be performed, namely: (1) the historic flood events must be translated into present-day discharges since we are interested in the effects of these historic events in present times, and (2) a continuous data set is required to perform a traditional flood frequency analysis. In this study, a 1D-2D coupled hydraulic flood model is set up with which historic flood events are routed over the current geometry of the Rhine river. Furthermore, a bootstrap approach is proposed to enable the creation of a continuous data set of annual maximum discharges. The data set near Lobith (the German-Dutch border) is extended from 120 to 700 years resulting in a tremendous reduction of the $95 \%$ confidence interval of the fitted flood frequency relation for large return periods.
\end{abstract}

\section{Introduction}

Each year, floods result in tremendous damage and loss of life worldwide. It is expected that floods become a growing problem as societies become wealthier resulting in more material damage (Brazdil et al. 2006). It is foreseen that annual flood losses in Europe increase fivefold by 2050 (EEA, 2016).

Flood defences are constructed to protect the hinterland from severe inundations. These flood defences are generally designed according to an appropriate safety level that is determined based on a statistical return period or exceedance probability. In many countries worldwide, flood frequency analyses (FFAs) are used to link design discharges to return periods (Benito et al 2004, Machado et al. 2015) since these analyses are straightforward to apply. These analyses consist of a technique to fit a probability distribution function to a series of annual maximum discharges for defining probabilities of future flood events. In short, FFAs consists of three steps, namely (Khaliq et al. 2006):

1. Selecting a probability distribution function.

2. Choosing a parameter estimation method.

3. Providing an estimate of the uncertainty associated with the parameters of the probability distribution function.

In this study, we are mostly interested in the last step: the uncertainty of the parameter estimates resulting in a
95\% confidence interval of the fitted flood frequency relation. Design discharges are generally designed according to return periods in the order of 100 to 1,000 years while discharges have been measured for a much shorter time period. In the Netherlands (used as a case study), the maximum safety level even corresponds with a return period of 100,000 years while discharges have been measured since 1901. Using this relatively short data set of annual maximum discharges to compute the design discharge corresponding to a return period of 100,000 years results in large uncertainties caused by extrapolation. Many studies have shown that this uncertainty can be reduced by extending the data set of measured annual maximum discharges with historic flood events (Bomers et al 2019a; Neppel et al. 2010; Sheffer et al. 2003). However, a traditional FFA analysis requires a continuous data set of annual maximum discharges. Since adding historic flood events to a data set of annual maximum discharges does not result in an continuous data set, a traditional FFA cannot be performed. To overcome this problem, Bayesian statistics are generally used in literature (O'Connell et al. 2002; Parkes and Demeritt 2016; Reis and Stedinger 2005). With Bayesian statistics, the fully posterior distribution of the parameters of a probability distribution function can be computed based on some prior knowledge. However, the results of Bayesian statistics are still questionable (Bomers et al. 2019b; Neppel et al. 2010). Furthermore, current policies are generally based

${ }^{a}$ Corresponding author: a.bomers@ utwente.nl

DOI 10.3311/FLOODRisk2020.24.2 
on a traditional FFA which is more straightforward and understandable by policy-makers. Therefore, this study proposes a bootstrap approach with which it is possible to extend a data set of annual maximum discharges with historic flood events and thus creating a continuous data set. Hence, a traditional flood frequency analysis can be performed.

Another problem which is generally not addressed in literature is related to the magnitude of the historic flood events in present times. Flood frequency relations are computed for the design of future flood protection measures. Therefore, we are not interested in the magnitude of the historic flood events, but in the consequences of such a flood event in present times. Most rivers in the world have changed significantly in the last 100 years caused by anthropogenic interventions. Therefore, the reconstructed historic flood events must be translated into present-day discharges: discharges that occur now if a flood event of the same magnitude as the reconstructed historic flood event occurs. In this study, this translation is referred to as normalization. To summarize, the objective of this study is to decrease the $95 \%$ confidence intervals of flood frequency relations for large return periods. This objective can be reached with the following two steps:

- $\quad$ Setting up a bootstrap approach to be able to extend the data set of annual maximum discharges with historic flood events and thus creating a continuous data set.
- $\quad$ Setting up a hydraulic modelling approach to be able to normalize the historic flood events to present-day discharges.

\section{Methodology}

Lobith is used as a case study representing the location where the Rhine river enters the Netherlands (Fig. 1). Here, discharge measurements have been performed since 1901. This data set can be extended with: (1) reconstructed maximum discharges based on water level measurements near Lobith (period 1866-1900) and (2) water level measurements of surrounding sites (period 1772-1865). Toonen (2015) used a regression function to translate maximum measured water levels into maximum discharges resulting in a continuous data set of annual maximum discharges starting from 1772 (Fig. 2). This continuous data set can be extended with historic flood events at Cologne, Germany, reconstructed by Herget and Meurs (2010). Historical documents providing information about occurred maximum water levels during the historic flood events were translated into maximum discharges based on a reconstruction of the cross-sectional area of the river. However, since these historical sources, the reconstructed cross-sectional area and the friction of the river bed were all uncertain, the reconstructions of the maximum discharges are uncertain as well. These uncertainties are included in the hydraulic flood modelling

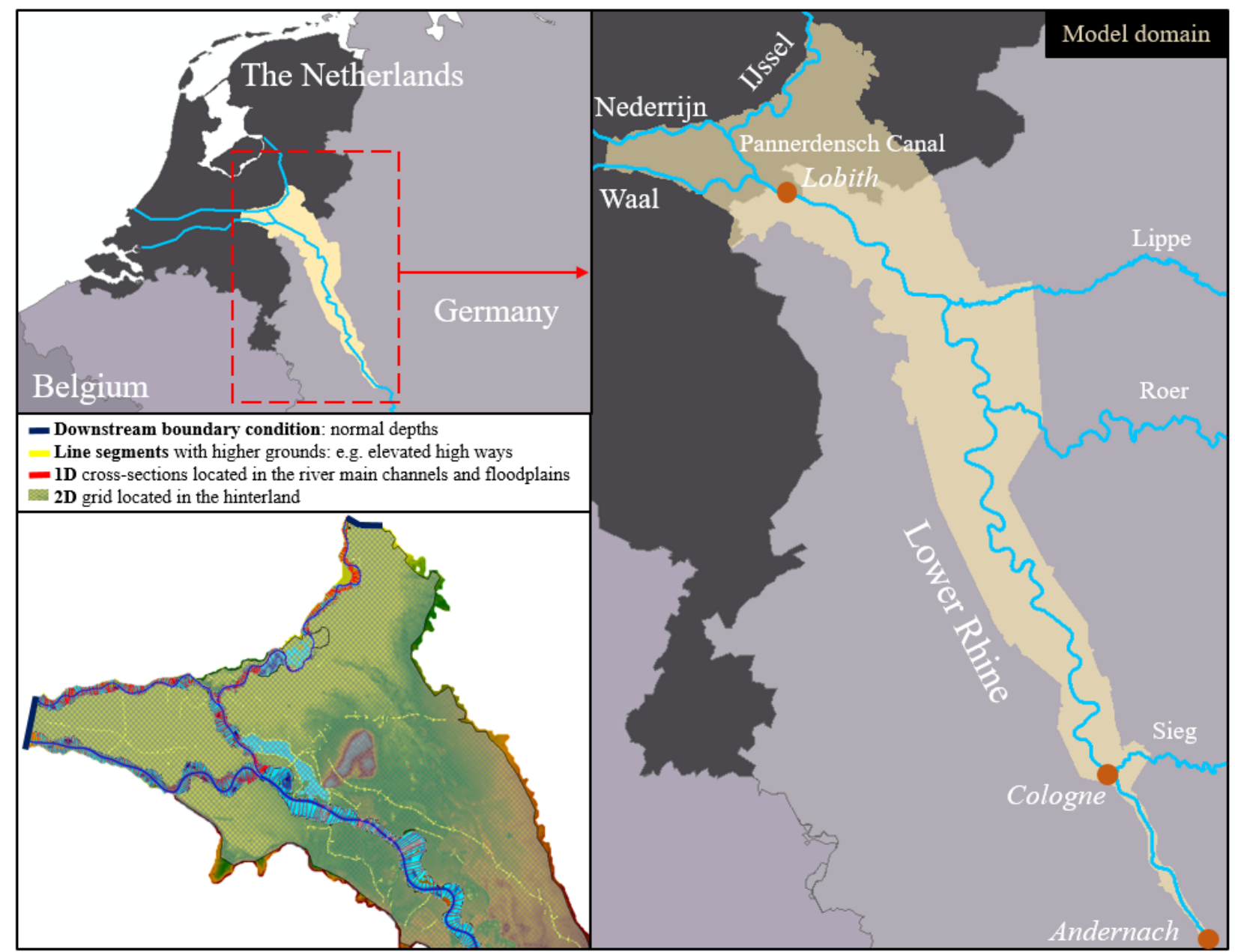

Figure 1. The model domain of the hydraulic modelling approach. 


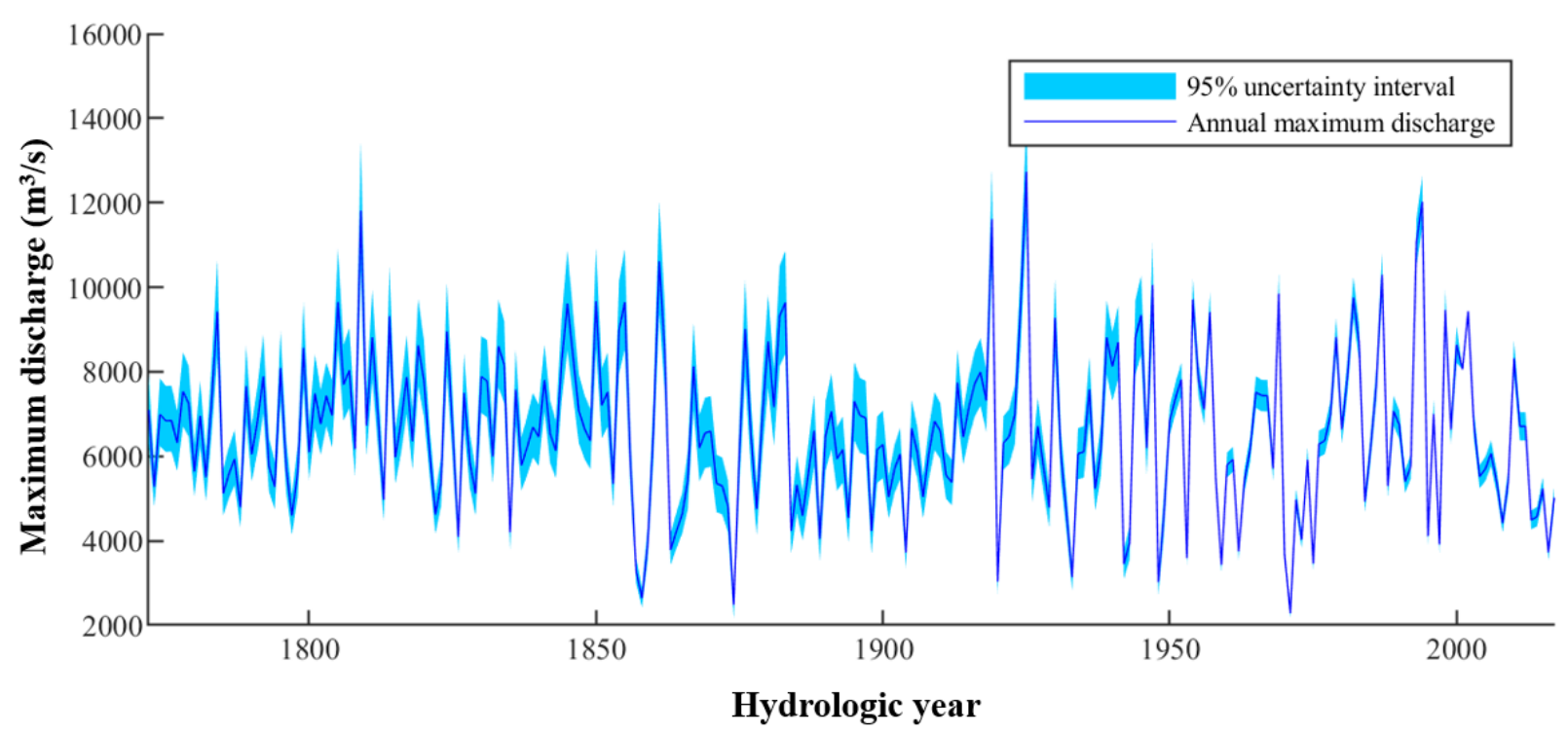

Figure 2. Annual maximum discharges of the discharge reconstructions based on measured water levels (Toonen, 2015) covering the period 1772-1900 and of the measured discharges covering the period 1901-2018. The light blue area represents the $95 \%$ uncertainty interval caused by uncertainties in water level measurements, translation of water level measurements into discharges and discharge measurements. Taken from Bomers et al. (2019b).

approach described in section 2.1. With this approach the historic flood events near Cologne are normalized to present-day discharges near Lobith. The bootstrap approach to create a continuous data set is provided in section 2.2. Finally, in section 2.3 the FFA to fit the floodfrequency relation is explained.

\subsection{Hydraulic flood modelling approach}

\section{Hydraulic model}

To simulate the effects of the historic flood events in present times, a one-dimensional-two-dimensional (1D2D) coupled hydraulic model is set up. HEC-RAS (v. 5.0.3), developed by the Hydrologic Engineering Centre (HEC) of the US Army Corps of Engineers is used to perform the flood simulations.

The model domain stretches from Andernach (upstream boundary) till the Dutch delta (downstream boundaries) (Fig. 1). An data set of the expected 2025 geometry provided by the Dutch Ministry of Infrastructure and Water Management and the Landesamt für Natur, Umwelt und Verbraucherschutz (LANUV) of NorthrhineWestfalia is used as input DEM. Furthermore, this data set contains land use information which can be translated into Manning's roughness coefficients, and the location and heights of the flood defences.

In the flood model, the main channels and floodplains are schematized with $1 \mathrm{D}$ profiles whereas the hinterland is discretized on a 2D grid (Fig. 1). These 1D profiles and 2D grid cells are coupled by a so-called 'lateral structure' having the dimensions of the dikes protecting the hinterland from floods. The weir-equation is used to compute the amount of water transferred from the 1D profiles into the $2 \mathrm{D}$ grid cells and vice versa. The hinterland is schematized with a $2 \mathrm{D}$ grid since $1 \mathrm{D}$ profiles are not capable of capturing the complex potential flow patterns in these areas.

A hydrograph is used as upstream boundary condition. Hydrographs are also used as boundary conditions for the three main tributaries along the Lower Rhine: the Sieg, the Ruhr and the Lippe rivers. Normal depths are used as downstream boundary conditions which are computed with the Manning's equation (Brunner, 2016). This equation computes the water depths based on the slopes of the rivers, the Manning's roughness coefficients and the cross-sectional averaged flow velocities.

Even though the dikes and flood defences along the Lower Rhine have been strengthened and heightened the last decade, the historic flood events may still lead to dike breaches in present-times. Therefore, a dike breach model is implemented. This dike breach model makes use of the built-in time growth template in HEC-RAS. This template assumes an S-function for the dike breach growth: the dike breach width increases slowly at first and then accelerates as time advances, and finally slows down again when the breach is almost developed till its final predefined width (Gee, 2010).

The flood model is calibrated by altering the friction values of the main channel beds such that simulated water levels are close to measurements (Bomers et al. 2019c). The 1995 and 1993 flood events are used for calibration and validation, respectively, representing the two largest flood events of the last 50 years. In total, 14 measurement stations are present along the Lower Rhine and Dutch Rhine river branches. After calibration, the flood model simulated water levels with an absolute average difference of approximately $1 \mathrm{~cm}$ compared to measured water levels for the 1995 flood event. For the 1993 flood event, an absolute average difference of $7 \mathrm{~cm}$ was found. 


\section{Monte Carlo analysis}

Since the consequences of large flood events in present-times are highly uncertain, a Monte Carlo analysis is performed to include these uncertainties in the analysis. The most uncertain sources in the model and the ones that are therefore included in the flood modelling approach are:

- Upstream discharge hydrograph: both the shape and peak value.

- Discharge hydrographs of the three tributaries along the Lower Rhine which depend on the upstream discharge hydrograph.

- Dike breach threshold in terms of critical water level indicating when the dike starts to breach. Failure mechanisms piping, macro-stability and combined overflow and wave overtopping are included in the analysis. In this way, the dike may also breach if the water levels are below the dike crest level.

- The dike breach formation time indicating the time until the dike breach has fully developed.

- The final breach width.

These input parameters are varied within the Monte Carlo analysis according to a Latin Hypercube sampling strategy resulting in different potential flood scenarios (Bomers et al 2019d). For each flood simulation, the upstream discharge wave is sampled according the uncertainty ranges of the historic flood events reconstructed by Herget and Meurs (2010) (Fig. 3). Also the shape of the discharge hydrograph is varied based on the data set of Hegnauer et al. (2014) which includes potential discharge waves that can occur under current climate conditions. Corresponding discharge hydrographs of the three tributaries are selected as well. Based on these inflows, the flood model computes the water levels in the various river branches. Each time step, the model evaluates if the simulated water levels exceed the sampled critical water levels. If this is the case, the dike will start to breach according to the sampled dike breach formation time and final breach width.
This Monte Carlo approach is used to normalize the 12 historic flood events reconstructed by Herget and Meurs (2010) for present times. For each flood event, 90 simulations are performed resulting in 90 potential flood scenarios. These simulations are used to compute the uncertainty interval of the normalized historic flood events near Lobith.

\subsection{Bootstrap method}

The data set of measured annual maximum discharges covering the period 1901-2018 is extended with the continuous data set of discharge reconstructions covering the period 1772-1900 (Toonen, 2015). Furthermore, this data set is extended with the 12 normalized historic flood events using the hydraulic flood modelling approach (section 2.1). Adding these normalized flood events to the data set does not result in a continuous data set of annual maximum discharges. However, a continuous discharge series is required to perform a traditional FFA. Therefore, a bootstrap approach is developed with which it is possible to sample discharges for the years of which no historical information is available, i.e. the missing years. The continuous 1772-2018 data set is resampled for the missing years using a bootstrap method based on sampling with replacement. Two assumptions are required before the bootstrap method can be applied:

- The length of the continuous data set: since we do not know the start of the historical time period, the length of the data set is unknown. Assuming that the data set starts with the first known historic flood event will overestimate the flood probabilities since the true length of the data set is underestimated (Hirsch and Stedinger 1987; Schendel and Thongwichian 2017).

- The perception threshold representing a threshold for which it is assumed that flood events were recorded in the historical times (e.g. written documents, flood marks on buildings) before

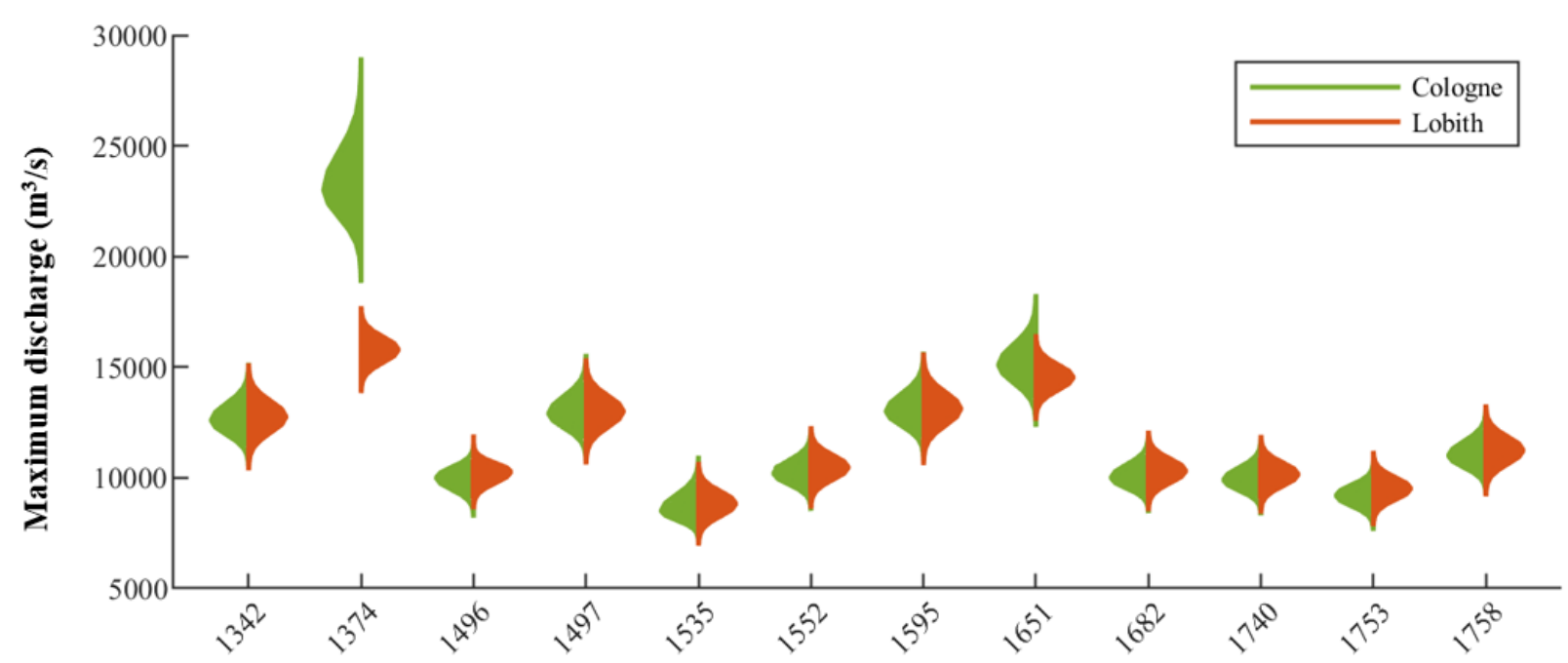

Hydrologic year

Figure 3. Maximum discharges of the historic flood events near Cologne (green) and corresponding present-day discharges near Lobith (orange). Taken from Bomers et al (2019b). 
water level and/or discharge measurements were conducted.

To make an assumption about the length of the extended continuous data set, Schendel and Thongwichian (2017) propose the following equation:

$$
M=L+\frac{L+N-1}{k}
$$

where $\mathrm{M}$ represents the length of the historical period (years) before water level and/or discharge measurements were conducted, L represents the number of years from the first historic flood event to the start of the systematic record (here: 431 years), $\mathrm{N}$ the length of the systematic time period representing the period for which water level and/or discharge measurements have been conducted (here: 247 years), and $\mathrm{k}$ represents the number of floods exceeding the perception threshold throughout the entire extended data set (here: 28). Using equation (1) yields a continuous data set from 1317 to 2018 .

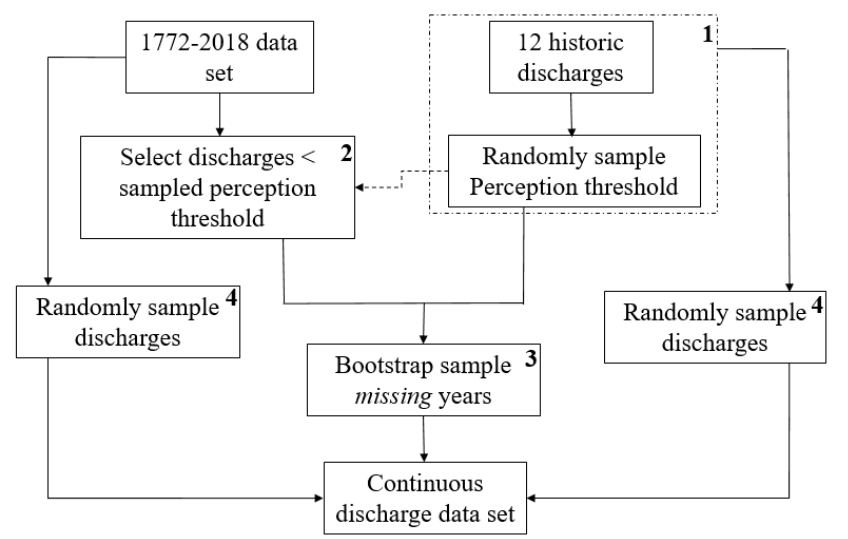

Figure 4. The bootstrap approach.

To create the continuous data set, the missing years between the historic flood events are sampled. However, the sampled discharges must be smaller than the perception threshold. This perception threshold is considered to be equal to the smallest historic flood event (here: 1535 flood event, Fig. 3) (Parkes and Demeritt, 2016). However, since the present-day discharge of this event is uncertain, also the perception threshold is uncertain. Therefore, the perception threshold is considered as a random uniformly distributed parameter in the bootstrap approach based on the 95\% confidence interval of the 1535 flood event near Lobith.

The bootstrap approach is given in Fig. 4 and consists of the following steps:

1. Selecting the perception threshold based on the results of the normalized historic flood events.

2. Select all discharges from the continuous data set of annual maximum discharges the discharges that are smaller than the perception threshold.

3. Sample (bootstrap sample with replacement) a discharge for the missing years based on the data set created under step 2 .

4. Since both the data set of measured discharges (light blue area in Fig. 2) as well as the normalized historic flood events are uncertain (orange areas in Fig. 3), a value must be randomly sampled based on the $95 \%$ uncertainty interval of these discharges.
Adding the data sets created under steps 3 and 4 results in a continuous data set of annual maximum discharges covering the period 1317-2018. However, each bootstrap sample results in a slightly different continuous data set. Therefore, 5,000 data sets are created which are used to construct a flood frequency relation and corresponding confidence interval as described in section 2.3.

\subsection{Flood frequency analysis}

For each of the 5,000 continuous data sets, an FFA is performed resulting in 5,000 flood frequency relations. The average is taken to compute the final position of the flood frequency relations whereas the $95 \%$ confidence interval is based on the parameter uncertainties of the considered distribution function. In this study, the Generalized Extreme Value (GEV) distribution function is used as probability distribution function since several studies have shown the applicability of this distribution on the flood regime of the Rhine river (Toonen, 2015; Chbab et al. 2006; Te Linde et al. 2010; Bomers et al. 2019b). With this distribution, we fit the annual maximum discharges to its probability of occurrence using the maximum likelihood fitting method. The maximum discharge at Lobith is restricted to a maximum value due to overflow and dike breaches along the Lower Rhine. Therefore, the flood frequency relation must converge towards a maximum value for extremely large return periods which can be controlled with the GEV distribution. The GEV distribution is described as follow:

$$
F(x)=\exp \left\{-\delta\left(\frac{x-\mu}{\sigma}\right)^{\frac{1}{\delta}}\right\}
$$

where $\delta$ represents the shape parameter controlling the skewness and kurtosis of the distribution which both influence the upper flexible tail of the distribution function, $\mu$ represents the location parameter indicating where the origin of the distribution function is positioned and $\sigma$ represents the scaling parameter describing the spread of the data.

\section{Results}

\subsection{Normalization of the historic flood events}

Fig. 3 shows the annual maximum discharges of the historic flood events in present times near Lobith. The 1374 flood event, representing the largest flood of the last 1,000 years, decreases significantly in downstream direction. This flood event is much larger than the current discharge capacity of the Lower Rhine resulting in large overflows. Moreover, dike breaches along the Lower Rhine decrease the maximum discharge even further. Therefore, we conclude that the maximum discharge that can enter the Netherlands at Lobith is restricted to a maximum value caused by the discharge capacity of the Lower Rhine. However, the large overflows and dike breaches result in tremendous overland flow patterns through the hinterland. As a result, large parts of the Netherlands can be inundated while the discharge at Lobith is still below its maximum value set for policy 
purposes (Fig. 5). The effect of these overland flow patterns on flood risk is addressed in more detail in Bomers et al. (2019d). Here, we only focus on the maximum discharge at Lobith and do not discuss potential overland flow patterns.

The other normalized flood events have discharges near Lobith which are in the same order of magnitude as the historic flood events near Cologne (Fig. 3) since these flood events had discharges which were below the current discharge capacity of the Lower Rhine. However, dike breaches may occur before water levels exceed the dike crest due to failure mechanisms piping and macrostability. Therefore, the flood event of 1651 slightly decreases in downstream direction. The present-day discharges of the remaining flood events increase in downstream direction due to the inflow of the tributaries along the Lower Rhine.

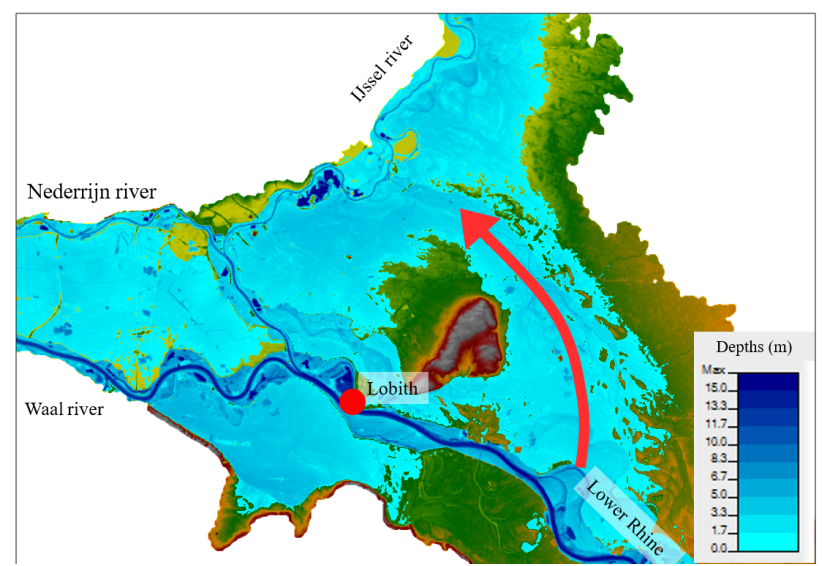

Figure 5. Inundation map of the 1374 flood event in present times. This map shows that a large amount of water can flow towards the hinterlands of the Netherlands due to overflow and dike breaches along the Lower Rhine before the river enters the Netherlands near Lobith.

\subsection{Flood frequency analysis}

In this section, the flood frequency relations are presented for both the measured annual maximum discharges from 1901 (data set currently used for policy purposes) and the extended data set with a length of approximately $\sim 700$ years (Fig. 6). The location and shape of the two fitted flood frequency relations are more or less the same (Fig. 6 and Table 1). However, we do find a significant reduction of the $95 \%$ confidence interval of the flood frequency relation due to the extension of the data set of annual maximum discharges. For the discharge corresponding to a return period of 1,250 years the uncertainty decreases from $10,200 \mathrm{~m}^{3} / \mathrm{s}$ to $2,930 \mathrm{~m}^{3} / \mathrm{s}$. For the discharge corresponding to a return period of 100,000 year this uncertainty reduction is even larger, namely from $18,280 \mathrm{~m}^{3} / \mathrm{s}$ to $4,980 \mathrm{~m}^{3} / \mathrm{s}$ (Table 1 ). Specifically, the upper $95 \%$ confidence interval of the tail of the fitted flood frequency relation is reduced. This is of high importance for policy-makers since it contributes to prevention of over-designing the flood defences resulting in unnecessary cost investments.

Even though the maximum discharges of the historic flood events are highly uncertain themselves due to the uncertain historical documents used (Herget and Meurs, 2010), the normalization step resulted in a decrease of this uncertainty for the largest flood events (e.g. 1374). These large flood events have a large effect on the tail of the fitted probability distribution function and therefore decreasing this uncertainty is of high importance. However, the normalized historic flood events still have an uncertainty in the order of $3,380-5,090 \mathrm{~m}^{3} / \mathrm{s}$. Adding these uncertain normalized discharge reconstructions to the data set of annual maximum discharges still results in a significant decrease of the total uncertainty of the flood frequency relation since the statistical extrapolation uncertainty is reduced. Extrapolation uncertainty represents the largest source of uncertainty in the domain of large return periods.

\begin{tabular}{|c|c|c|}
\hline & $\begin{array}{c}\text { 1901-2018 } \\
\text { data set }\end{array}$ & $\begin{array}{c}\mathbf{1 3 1 7 - 2 0 1 8} \\
\text { data set }\end{array}$ \\
\hline Q10 & 9,270 & 8,910 \\
\hline Q100 & 12,080 & 11,630 \\
\hline Q1,000 & 14,120 & 13,730 \\
\hline$-2 \sigma$ & 10,630 & 12,570 \\
Q1,250 & 14,290 & 13,910 \\
$+2 \sigma$ & 20,840 & 15,490 \\
\hline$-2 \sigma$ & 11,350 & 14,510 \\
Q100,000 & 16,780 & 16,690 \\
$+2 \sigma$ & 29,630 & 19,490 \\
\hline
\end{tabular}

Table 1. Discharges $\left(\mathrm{m}^{3} / \mathrm{s}\right)$ and their $95 \%$ uncertainty intervals $( \pm \sigma)$ corresponding to several return periods $(\mathrm{Q} x)$ for the data set of measured annual maximum discharges (1901-2018) and the extended data set using the bootstrap approach (1317-2018).

\section{Conclusions}

We have set up a bootstrap approach to enable the inclusion of historic flood events in a traditional flood frequency analysis. However, before historical flood events can be added to the data set of measured annual maximum discharges, these events must be normalized meaning that the historical discharges must be translated into present-day discharges. To define the consequences of historic flood events in present times, the events were routed over current geometry using a 1D-2D coupled hydraulic flood model.

Using a 1D-2D coupled model to translate the historic flood events into present-day maximum discharges results in an accurate representation of potential flood scenarios. Many uncertain parameters can be included into the analysis, such as: dike breach locations, dike breach widths and formation times, and potential upstream discharge shapes. This information is essential for the estimation of the $95 \%$ confidence intervals of the maximum discharges of the historical flood events in present times. These confidence intervals can be included in the flood frequency analysis using a bootstrap approach. 
As a result, the uncertainty of the flood frequency relations is reduced.
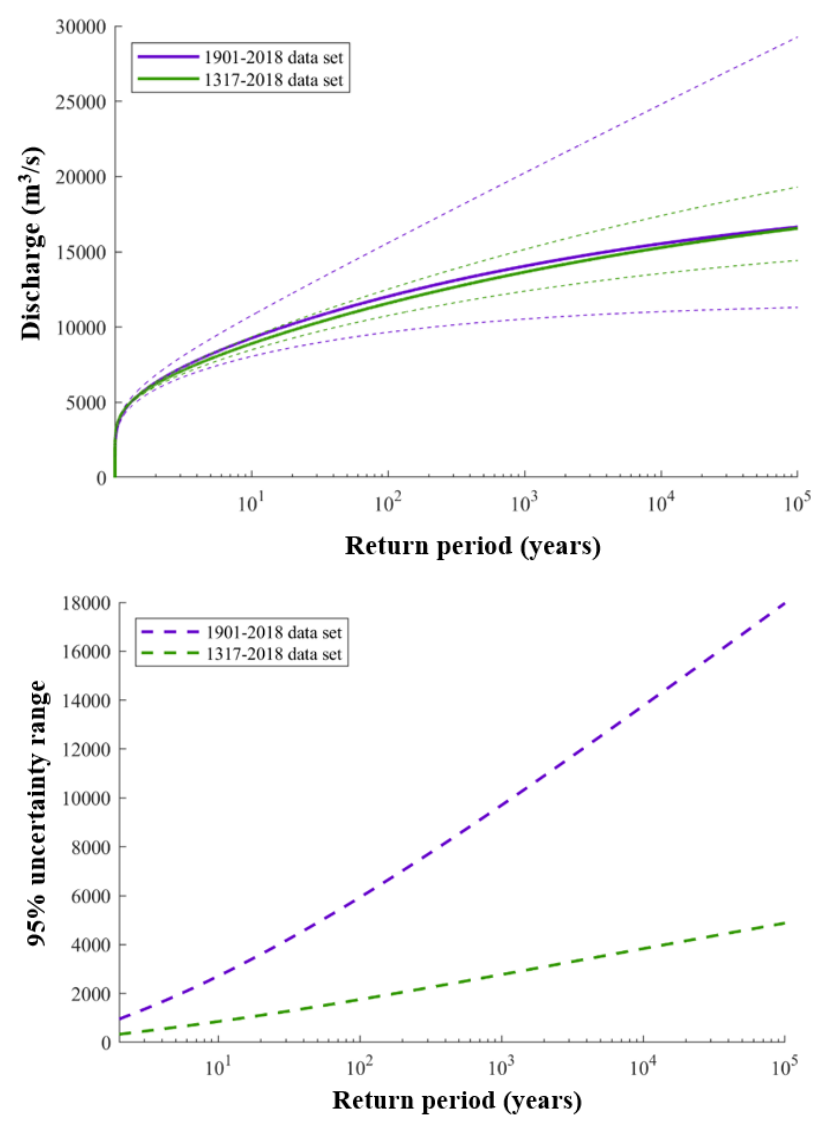

Figure 6. Flood frequency results of the data set of measured discharges (1901-2018) and the extended data set (1317-2018). The dashed lines in both figures represent the $95 \%$ confidence intervals.

In this study, the data set of 120 years of measured annual maximum discharges was extended with historic flood events with the oldest event dating back to 1342. A bootstrap sampling approach was used to create a continuous data set of approximately 700 years. The bootstrap approach shows that extending the data set of annual maximum discharges with historic flood events results in a tremendous reduction of the uncertainty of the flood frequency relation. This even accounts if the translated historic flood events into present-day discharges are highly uncertain themselves. This reduction is mainly caused by decreasing the extrapolation uncertainty of the data set of annual maximum discharges to design discharges with low probability of occurrence. Therefore, we conclude that the most important parameter influencing the uncertainty of flood frequency relations is the length of the considered data set. This is why we recommend to add historic information in future flood frequency analyses even if the information itself is highly uncertain.

\section{Acknowledgement}

This research is supported by the Netherlands Organisation for Scientific Research (NWO, project 14506) which is partly funded by the Ministry of
Economic Affairs and Climate Policy. Furthermore, the research is supported by the Ministry of Infrastructure and Water Management and Deltares. This research has benefited from cooperation within the network of the Netherlands Centre for River studies NCR (www.ncrweb.org).

The authors would like to thank the Dutch Ministry of Infrastructure and Water Management, Prof. Dr. Herget (University of Bonn) and Dr. Toonen (KU Leuven) for providing the data.

\section{References}

1. Benito G., M. Lang, M. Barriendos, C. Llasat, F. Francés, T. Ouarda, V. Thorndycraft, Y. Enzel, A. Bardossy, D. Coeur and B. Bobée (2004) Use of systematic, palaeoflood and historical data for the improvement of flood risk estimation. Review of Scientific Methods. Natural Hazards 31: 623-643

2. Bomers, A., B. van der Meulen, R.M.J. Schielen and S.J.M.H. Hulscher (2019a). Historic flood reconstruction with the use of an Artificial Neural Network, Water Resources Research 55(11): 96739688

3. Bomers A., R.M.J. Schielen and S.J.M.H. Hulscher (2019b) Decreasing uncertainty in flood frequency analyses by including historic flood events in an efficient bootstrap approach. Natural Hazards and Earth System Sciences 19: 1895-1908

4. Bomers, A., R.M.J. Schielen and S.J.M.H. Hulscher (2019c) The influence of grid shape and grid size on river modelling performance. Environmental Fluid Mechanics 19(5): 1273-1294

5. Bomers, A., R.M.J. Schielen and S.J.M.H. Hulscher (2019d) Consequences of dike breaches and dike overflow in a bifurcating river system. Natural Hazards 97(1): 309-334

6. Brázdil R., Z.W. Kundzewicz and G. Benito (2006) Historical hydrology for studying flood risk in Europe. Hydrological Sciences Journal 51(5): 739764

7. Brunner G.W. (2016) HEC-RAS, River analysis system hydraulic reference manual, Version 5.0. Technical report February, US Army Corp of Engineers, Hydrologic Engineering Center (HEC), Davis, USA

8. Chbab, E. H., H. Buiteveld and F. Diermanse (2006) Estimating Exceedance Frequencies of Extreme River Discharges Using Statistical Methods and Physically Based Approach, Osterreichse Wasser- und Abfallwirtschaft 58: 35-43

9. EEA (2016) Floodplain management: reducing flood risks and restoring healthy ecosystems. Technical report, European Environment Agency, Copenhagen, Denmark, http://floodlist.com/europe/report-floodseurope-increase-fivefold-2050Benito 2004

10. Gee M. (2010) Use of breach process models to estimate Hec-Ras dam breach parameters. Proceedings of the 2nd joint federal interagency conference, Las Vegas, USA 
11. Hegnauer M., J.J. Beersma, H.F.P. van den Boogaard, T.A. Buishand and R.H. Passchier (2014) Generator of rainfall and discharge extremes (GRADE) for the Rhine and Meuse basins. Final report of GRADE 2.0. Technical report, Deltares, Delft, the Netherlands

12. Herget, J. and H. Meurs (2010) Reconstructing peak discharges for historic flood levels in the city of Cologne, Germany, Global and Planetary Change 70: 108-116

13. Hirsch, R.M. and J.R. Stedinger (1987) Plotting positions for historical floods and their precision, Water Resources Research 23: 715-727

14. Khaliq M.N., T.B. Ouarda, J.C. Ondo, P. Gachon and B. Bobée (2006) Frequency analysis of a sequence of dependent and/or non-stationary hydrometeorological observations: A review. Journal of Hydrology 329: 534-552

15. Machado M.J., B.A. Botero, J. López, F. Francés, A. Díez-Herrero and G. Benito (2015) Flood frequency analysis of historical flood data under stationary and non-stationary modelling. Hydrology and Earth System Sciences 19(6): 2561-2576

16. Neppel L., B. Renard, M. Lang, P.A. Ayral, D. Coeur, E. Gaume, N. Jacob, O. Payrastre, K. Pobanz and F. Vinet (2010) Flood frequency analysis using historical data: accounting for random and systematic errors. Hydrological Sciences Journal 55(2): 192-208

17. O'Connell D.R.H., D.A. Ostenaa, D.R. Levish and R.E. Klinger (2002) Bayesian flood frequency analysis with paleohydrologic bound data. Water Resources Research 38(5): 1058-1071,

18. Parkes B. and D. Demeritt (2016) Defining the hundred year flood: A Bayesian approach for using historic data to reduce uncertainty in flood frequency estimates. Journal of Hydrology 540:1189-1208

19. Reis D.S. and J.R. Stedinger (2005) Bayesian MCMC flood frequency analysis with historical information. Journal of Hydrology 313(1-2): 97-116

20. Sheffer N.A., Y. Enzel, G. Benito, T. Grodek, N. Poart, M. Lang, R. Naulet and D. Coeur (2003) Paleofloods and historical floods of the Ardeche River, France. Water Resources Research 39(12)

21. Schendel, T. and R. Thongwichian (2017) Considering historical flood events in flood frequency analysis: Is it worth the effort?, Advances in Water Resources 105: 144-153

22. Te Linde, A. H., J.C. Aerts, A.M. Bakker and J.C. Kwadijk (2010) Simulating low-probability peak discharges for the Rhine basin using resampled climate modeling data, Water Resources Research 46: 1-19

23. Toonen, W.H. (2015): Flood frequency analysis and discussion of non-stationarity of the Lower Rhine flooding regime (AD 1350-2011): Using discharge data, water level measurements, and historical records, Journal of Hydrology 528: 490-502 